\title{
Mapping of Multiple DNA Gains and Losses in Primary Small Cell Lung Carcinomas by Comparative Genomic Hybridization ${ }^{1}$
}

\author{
Thomas Ried, ${ }^{2}$ Iver Petersen, Heidi Holtgreve-Grez, Michael R. Speicher, Evelin Schröck, Stan du Manoir, and \\ Thomas Cremer
}

Institute of Human Genetics, University of Heidelberg, INF 328, 69120 Heidelberg [T. R., H. H-G., M. R. S., E. S., T. C.]; Institute of Pathology, University of Kiel [I. P.]; and Angewandte Tumorvirologie, Deutsches Krebsforschungszentrum, Heidelberg [S. D. M.], Germany

\begin{abstract}
Comparative genomic hybridization was applied for a comprehensive screening of under- and overrepresentation of genetic material in 13 autoptic small cell lung cancer specimens. The most abundant genetic changes include DNA losses of chromosome arms 3p, 5q, 10q, 13q, and 17p and DNA gains of 3q, 5p, 8q, and 17q. Amplification sites in these tumors were mapped to 22 chromosome bands. The most frequently involved band was 19q13.1 (4 cases). Bands 1p32, 2p23, 7q11.2, 8q24, and 13q33-34 were involved in two cases each.
\end{abstract}

\section{INTRODUCTION}

$\mathrm{CGH}^{3}$ is a new method to screen a tumor genome for genetic imbalances (1). DNA isolated from the tumor and reference DNA are labeled separately with different haptens. Equal amounts of both, tumor and reference genomic DNA, are hybridized to normal metaphase chromosome preparations together with an excess of unlabeled Cot1 fraction of human DNA. After the detection of the hybridized sequences with two fluorochromes, e.g., FITC for the tumor DNA and rhodamine for the reference DNA, the differences in fluorescence intensity values of the respective fluorochromes reflect the over- or underrepresentation of chromosomal sequences in the tumor genome. The technique has been used to detect genetic alterations of entire chromosomes or chromosomal subregions, as well as to map amplified genes on normal metaphase chromosomes in a variety of solid tumors (2-5). Also, formalin-fixed archived tumor material is suitable for this molecular cytogenetic technique because it requires solely tumor DNA (6).

Solid tumors account for about $90 \%$ of malignancies in man (7). Despite this high percentage, relatively few data on specific chromosomal aberrations are available as compared to hematological malignancies (8). This discrepancy is mainly due to the difficulties to apply cytogenetic banding techniques to solid tumor specimens. Therefore, alternative approaches to elucidate genetic changes in solid tumors have been introduced. These include interphase cytogenetics (9) of nuclei in tissue sections or isolated tumor nuclei using whole chromosome paint probes or region-specific probes $(10,11)$. Also, the detection of loss of heterozygosity by means of Southern blot analysis or PCR was applied to identify commonly deleted regions in tumor genomes (12). However, while these approaches have become very useful to evaluate copy number changes of certain chromosomal subregions or genes, they are not suitable for the routine assessment of genetic changes in entire tumor genomes.

Received 10/13/93; accepted 2/2/94.

The cost of publication of the article were defrayed in part by the payment of page charges. This article must therefore be hereby marked advertisement in accordance with 18 U.S.C. Section 1734 solely to indicate this fact.

${ }^{1}$ This study was supported by a grant from the Deutsche Krebshilfe and the Land Baden-Württemberg to T.C.

${ }^{2}$ To whom requests for reprints should be addressed. Present address: National Center for Human Genome Research, NIH, Building 49, Bethesda, MD 20892.

${ }^{3}$ The abbreviations used are: CGH, comparative genomic hybridization; FITC, fluorescein isothiocyanate; PCR, polymerase chain reaction; SCLC, small cell lung carcinoma; DAPI, 4,6-diamidino-2-phenylindole dihydrochloride; RFLP, restriction fragment length polymorphism; LOH, loss of heterozygosity; FISH, fluorescence in situ hybridization.
Here we report on the identification of DNA alterations in 13 primary SCLC using CGH. Consensus deletion regions were identified for chromosomes $3 p, 5 q, 10 q, 13 q$, and $17 p$, whereas a consistent overrepresentation of chromosomes $3 q, 5 p, 8 q$, and $17 q$ was observed. The SCLC specimens revealed 22 different amplified regions. The chromosomal mapping positions of these amplified sequences were determined after CGH on normal metaphase and prometaphase chromosomes.

\section{MATERIALS AND METHODS}

Tumor Samples. Tumor specimens $(n=13)$ were collected at postmortem examination 3-24 h after the patients died. One aliquot of the sample was frozen in liquid nitrogen and kept at $-80^{\circ} \mathrm{C}$ until DNA extraction. Genomic DNA was prepared by Proteinase $\mathrm{K}$ digestion and phenol-chloroform extraction (13). A second aliquot was submitted to formalin fixation and paraffin embedding. The diagnosis of a SCLC was established in every case according to the WHO guidelines on hematoxylin and eosin-stained formalin-fixed tissue sections (14). Multiple distant metastases were observed in 12 of 13 cases. One patient revealed only local lymph node metastases (case no. 11).

CGH Analysis. CGH analysis was done according to the protocol by Du Manoir et al. (2) with minor modifications. Genomic DNA from a healthy male donor was labeled in a standard nick translation reaction substituting dTTP by digoxigenin-11-dUTP (Boehringer Mannheim); tumor DNA was labeled accordingly with biotin-16-dUTP (Boehringer Mannheim). The DNase I concentration in the labeling reaction was adjusted in order to reveal an average fragment size of 500-1000 base pairs.

For CGH, $200 \mathrm{ng}$ of digoxigenin-labeled reference DNA and $200 \mathrm{ng}$ of biotin labeled tumor DNA were ethanol precipitated in the presence of $10 \mu \mathrm{g}$ of salmon sperm DNA and $30 \mu \mathrm{g}$ of the Cot1 fraction of human DNA (BRL). This excess of Cot1 DNA is required to prevent the ubiquitous hybridization of interspersed repetitive sequences contained in the tumor and reference DNA probes. The probe mixture was dried and resuspended in $10 \mu$ l hybridization solution [ $50 \%$ formamide, $2 \times \operatorname{SSC}(0.15 \mathrm{M} \mathrm{NaCl}, 0.015 \mathrm{M} \mathrm{Na}$-citrate) and $10 \%$ dextran sulfate]. The DNA was denatured at $76^{\circ} \mathrm{C}$ for $5 \mathrm{~min}$ and allowed to preanneal at $37^{\circ} \mathrm{C}$ for $60 \mathrm{~min}$. Reference metaphase spreads were prepared following standard procedures from peripheral blood lymphocytes of a healthy donor $(46, \mathrm{XX})$. The chromosome preparations were denatured separately at $80^{\circ} \mathrm{C}$ in $70 \%$ deionized formamide and $2 \times$ SSC for $2 \mathrm{~min}$ and dehydrated through an ethanol series $(70,90$, and $100 \%)$. The probe mixture was then applied to the denatured metaphase chromosomes under a coverslip $\left(18 \mathrm{~mm}^{2}\right)$, sealed with rubber cement, and hybridized for 4 days at $37^{\circ} \mathrm{C}$.

Posthybridization steps were performed as described (15). The biotinylated sequences were detected with FITC conjugated to avidin (Vector laboratories). Probe sequences haptenized with digoxigenin were visualized with antidigoxigenin Fab fragments conjugated to rhodamine. Chromosomes were counterstained with DAPI and embedded in an antifading agent (DABCO; Sigma Chemical Co.) to reduce photobleaching.

Digital Image Analysis. Fluorescence was detected using a Zeiss Axiophot epifluorescence microscope. The fluorescence banding pattern obtained after DAPI staining was used for chromosome identification. FITC and rhodamine fluorescence, specific for the tumor and the reference genome, respectively, were quantified as gray level images by a charge-coupled device camera (Photometrics, Tucson, AZ). After background fluorescence measurements, fluorescence ratio images (Fig. 1B) were calculated as described (2). The ratio profiles of individual reference chromosomes were determined by a program that was developed in our laboratory by S. du Manoir (5) and run on a Macintosh Quadra 950. Briefly, after the determination of the chromosomal 

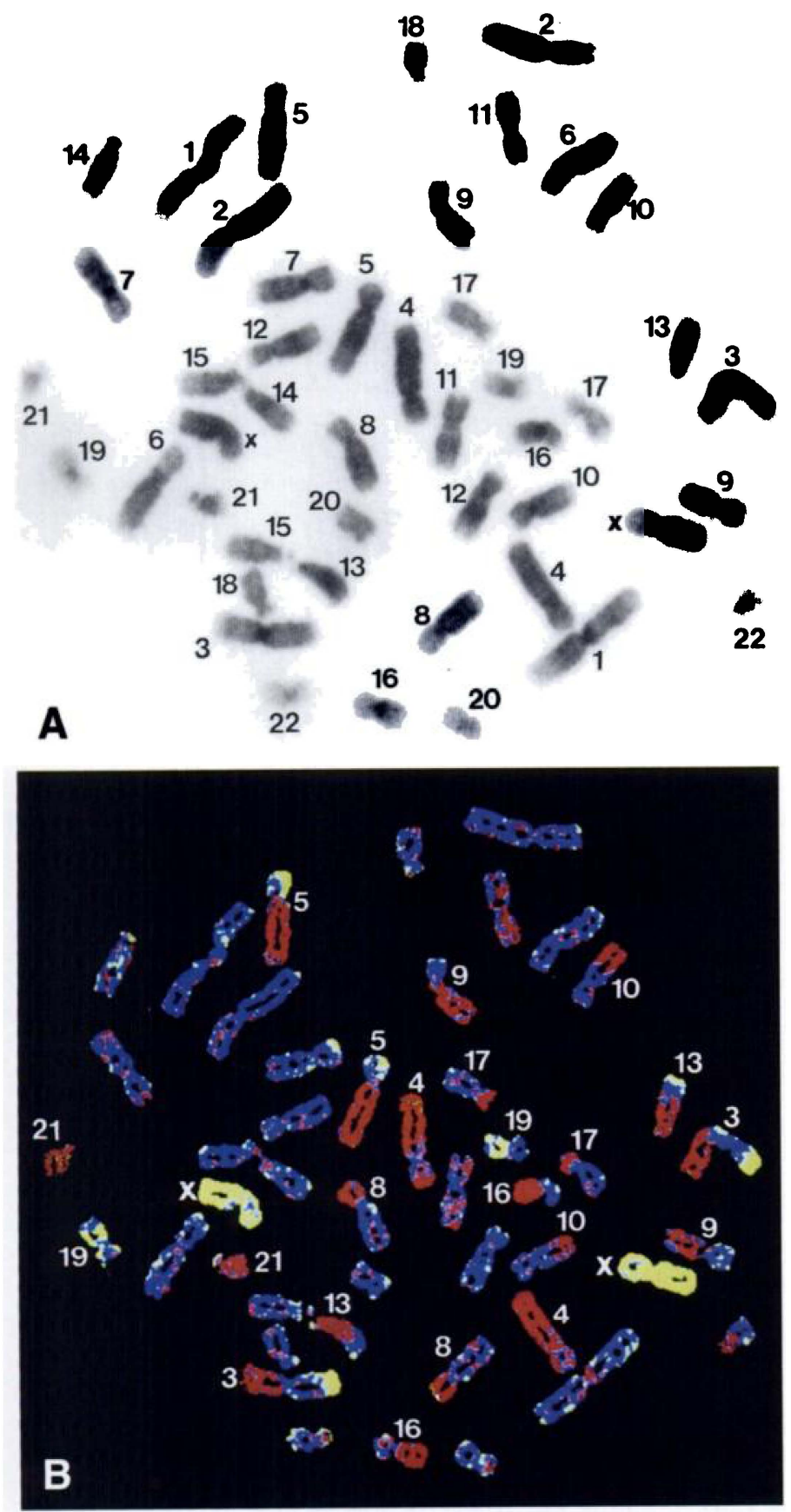

Fig. 1. Evaluation of the CGH analysis of SCLC case no. 12. A, DAPI-staining of normal metaphase chromosomes. The banding pattern was used for chromosome identification (numbers). $B$, display of fluorescence ratio image of the same metaphase spread as in $A$ after CGH with SCLC DNA. A three-color look-up table was chosen for the visualization of pixel by pixel FITC:rhodamine ratios. Blue, balance between the FITC and rhodamine values. Green, overrepresentation of DNA in the tumor. Red, loss of tumor DNA at the corresponding sequences. The chromosomes involved in aberrations in this SCLC case are labeled with the respective numbers. Note the consistency of the CGH results by comparing the values on the homologous chromosomes.

axis for each chromosome in every metaphase, individual FITC and rhodamine profiles were calculated. These were used for the computation of the ratio (FITC:rhodamine) profiles. Theoretically, a monosomy of certain chromosomes in the tumor would result in a ratio value of 0.5 and a trisomy in a value of 1.5. Values above 2 were regarded as amplified regions. The mean of the individual ratio profiles from five metaphase spreads were calculated (Fig. 2). The three vertical lines on the right side of the chromosome idiogram represent different threshold values between the tumor and the reference DNA. The central line corresponds to a balanced state, as defined as the most frequently observed value. The right and left lines reflect the threshold values that would be present if $50 \%$ of the cell population carries either a monosomy or a trisomy for a certain chromosome. Thus, these values are 0.75 and 1.25 , respectively. The curve shows the ratio profile that was computated as the mean value of five metaphase spreads. The gray boxes in Fig. 2 represent heterochromatic chromosome regions that cannot be interpreted. In these regions, very low FITC and thodamine fluorescence intensities were recorded due to the suppression with Cot1 DNA. Accordingly, fluorescence ratios indicating copy number changes could not be calculated. CGH experiments using, as the test genome, DNA extracted from healthy donors versus the reference DNA used in these experiments did not result in values beyond the defined thresholds.

\section{RESULTS}

An example of the experimental data after CGH analysis of SCLC case no. 12 is presented in Figs. 1 and 2. The fluorescence banding pattern of a normal lymphocyte metaphase spread after DAPI staining is shown in Fig. 1A. This G-banding pattern was used for chromosome identification. Based on the values of the FITC and rhodamine fluorescence, a ratio image was generated and is displayed using a look-up table (Fig. 1B). Blue indicates equal copy numbers in the two genomes. Green represents an overrepresentation in the tumor genome, while red is DNA loss. The loss of chromosome $3 p$ is obvious. The frequently observed loss of chromosome $5 q$ was accompanied by an overrepresentation of $5 p$. Furthermore, amplification sites could be mapped to chromosome bands 3q27-28, 19q13.1, and Xq27. The average fluorescence profile that was calculated for each chromosome as the mean value of 5 metaphase spreads is exemplified for this case in Fig. 2. Shaded areas represent regions rich in repetitive DNA in which the profile could not be interpreted (see "Materials and Methods"). These average ratio profiles were used for the evaluation of chromosomal gains and losses in all cases.

An overview about all genetic alterations that were detected in 13 SCLCs is displayed in Fig. 3. Vertical lines on the left side of each chromosome idiogram represent loss of genetic material in the tumor, whereas those on the right side correspond to a gain. Changes in individual cases can be identified by the case number provided on the top of each line. Amplification sites are represented as solid squares or bars.

Chromosome 3 was most frequently affected and showed alterations in all except one case (no. 1). Total or at least partial loss of the short arm was a consistent finding. Additionally, the long arm showed an overrepresentation in 10 cases. Chromosome 5 revealed genetic imbalances in 10 of 13 cases. Again, the loss of genetic material on one arm (5q) was often accompanied by a gain on the other chromosome arm (5p). This combination occurred in $45 \%$ of the cases (6 of 13). The results of CGH analysis were compared with studies of loss of heterozygosity with three markers on chromosome $3 p$ located at 3p13-14 (16) and 3p24 $(17,18)$ and two markers inside the $A P C$ gene that were assayed by PCR-RFLP (19). In seven cases that were informative for these markers, the results were confirmed by CGHanalysis, e.g., values specific for DNA losses were consistent with LOH. In one case, however, LOH on chromosome $3 p$ was not confirmed by CGH (see "Discussion"). Chromosome 8 was involved in 7 of 13 cases (54\%). In five of these, an overrepresentation of the long arm was observed. The short arm of chromosome 17 was deleted in 8 of 13 cases $(61 \%)$.

Different amplification sites $(n=22)$ could be mapped to normal chromosomes. For high resolution mapping of the chromosomal location of the amplified regions, the CGH analysis was repeated on prometaphase chromosomes. Fig. 4 presents, as an example, a partial reference prometaphase spread with amplification sites visible at band 8q24.1 harboring the c-myc protooncogene (case no. 3). Most frequently, chromosomal band 19q13.1 was involved (4 cases). Sequences originating from chromosome bands $1 \mathrm{p} 32,2 \mathrm{p} 23,7 \mathrm{q} 11.2$, $8 q 24$, and 13q33-34 were each amplified in two cases. Amplification 

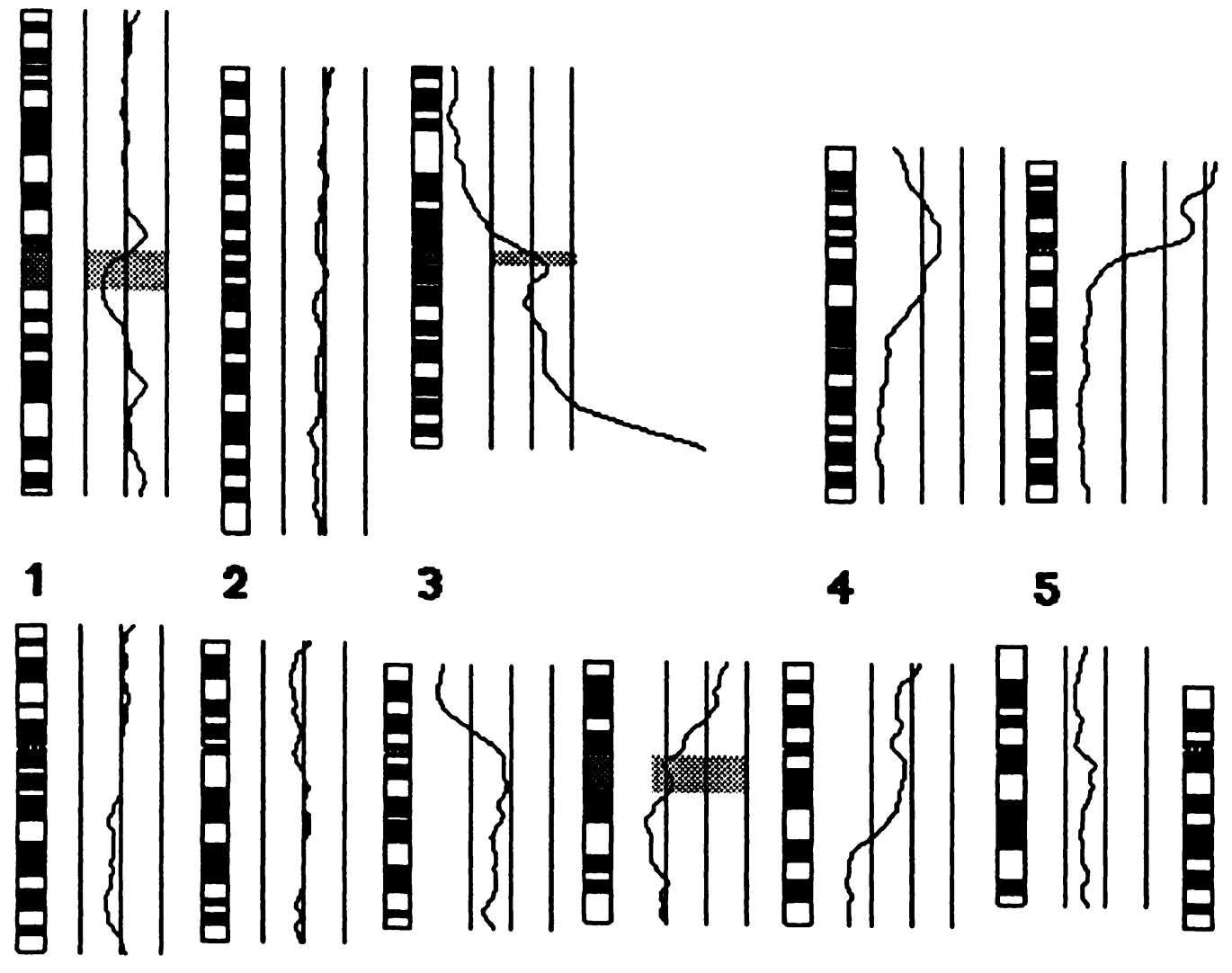

3

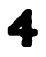

5

6

7

8
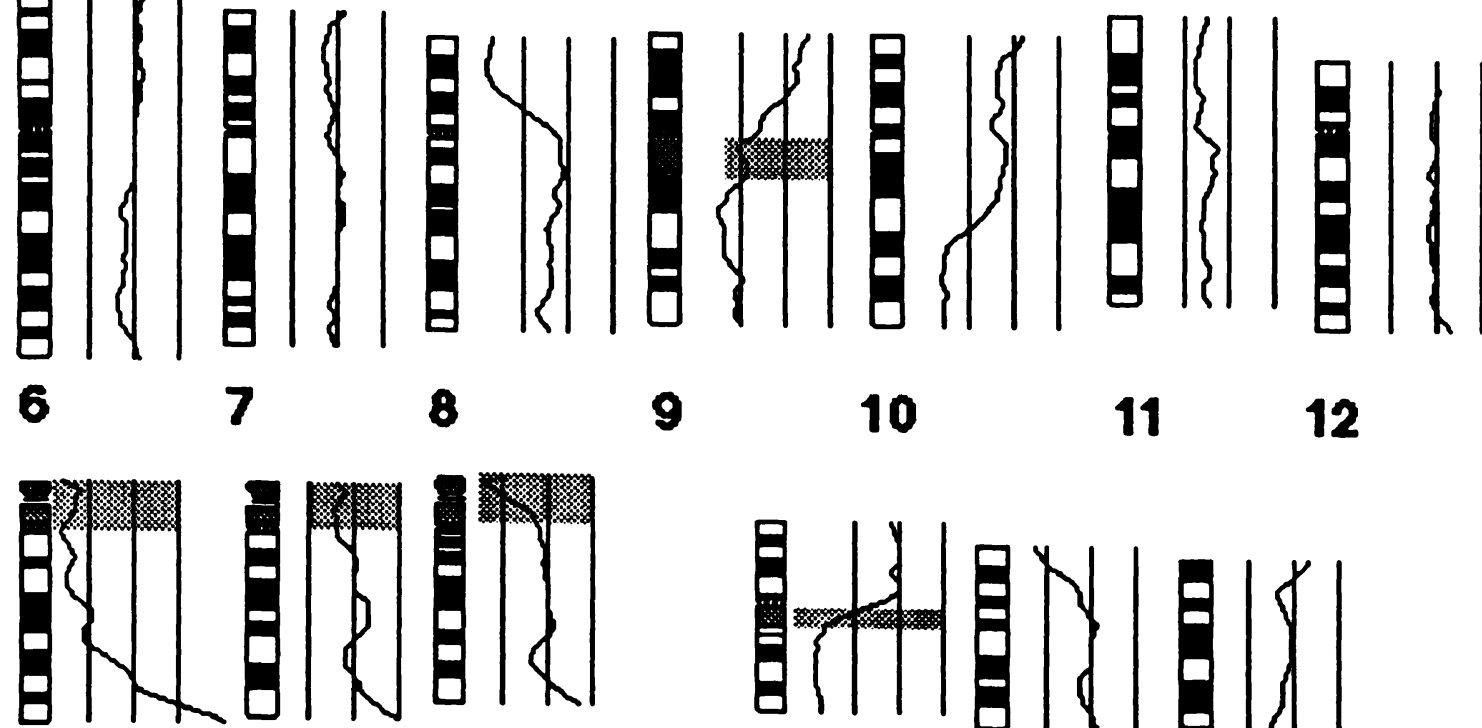

13

14

15

9

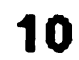

11
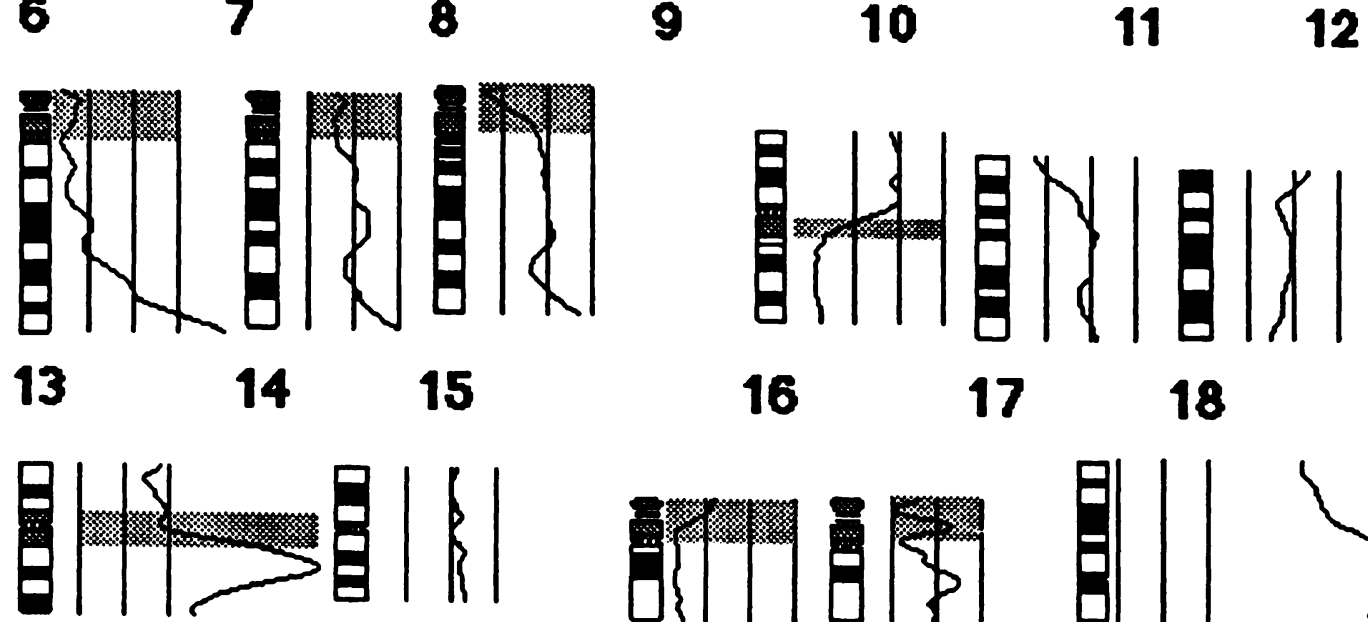

19

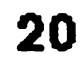

2122
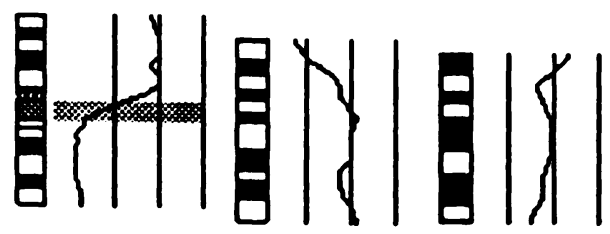

16

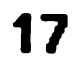

18
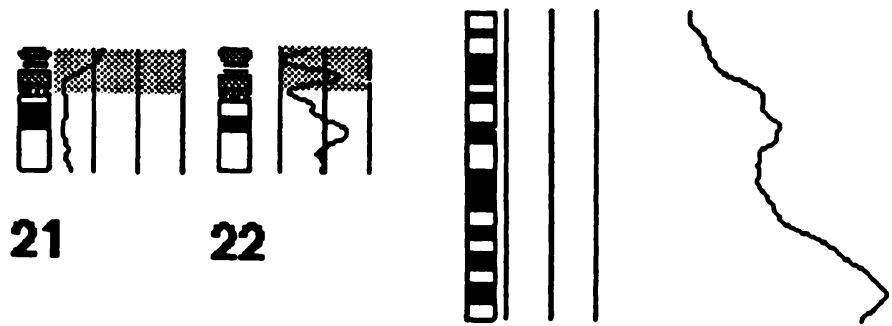

Fig. 2. Mean of the ratio profile calculation of five metaphase spreads of case no. 12. The three vertical lines on the right side of the chromosome idiograms represent different values of the fluorescence intensities between the tumor and the reference DNA. The values are $0.75,1$, and 1.25 from left to right. The ratio profile (curve) was calculated as a mean value of five metaphase spreads. Gray shaded boxes, chromosomal regions rich in heterochromatin that could not be interpreted due to the abundance of highly repetitive DNA. All
genetic changes that were visible in Fig. $1 B$ were confirmed after mean ratio profile measurements.

sites that occurred only once were observed at the following locations: $1 q 24,1 q 32,3 q 27-28,5 p 15,5 p 14,6 q 21,6 q 25,8 q 21,9 q 22,11 q 13$, 12p, 14q12-21, 15q24-25, 21q21, 22q11.2, Xp11.2, and Xq.

\section{DISCUSSION}

CGH has recently evolved as a powerful tool for the identification of chromosomal gains and losses in genomic DNA from tumor samples (1-6). Using CGH, we identified numerous chromosomal gains and losses as well as DNA amplification sites in 13 cases of primary SCLC.

Loss of genetic material was observed in decreasing frequency on chromosomes 3p, 5q, 17p, 13q, 10q, and 4q (Fig. 3). Most consistently, a loss of the short arm of chromosome 3 was observed in $90 \%$. This is also the most consistent finding that has been reported previously by means of cytogenetical (20-24) and molecular biology 

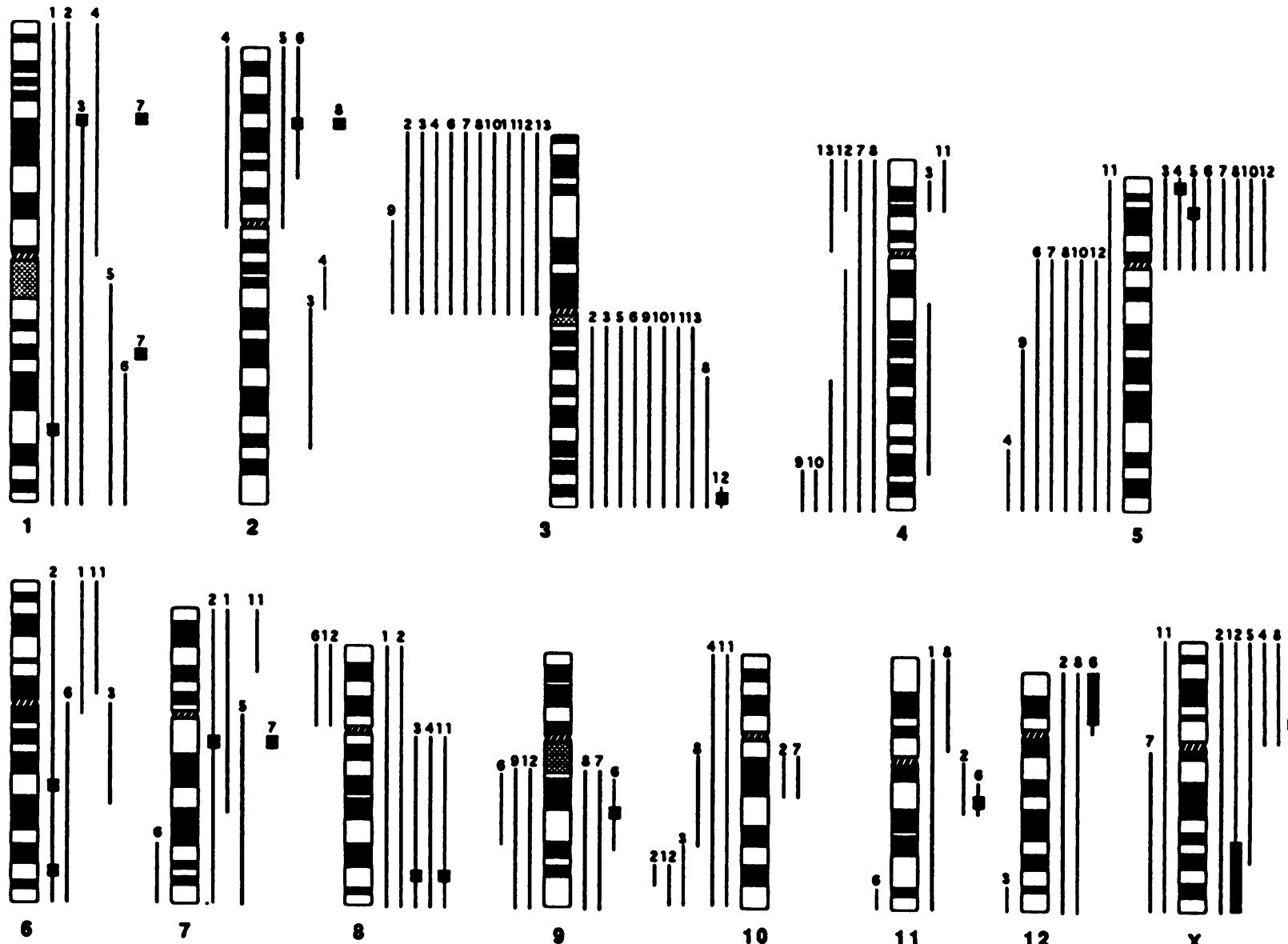

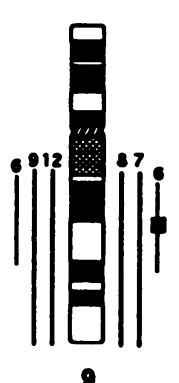

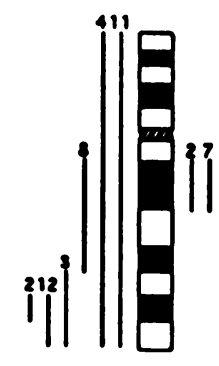

10
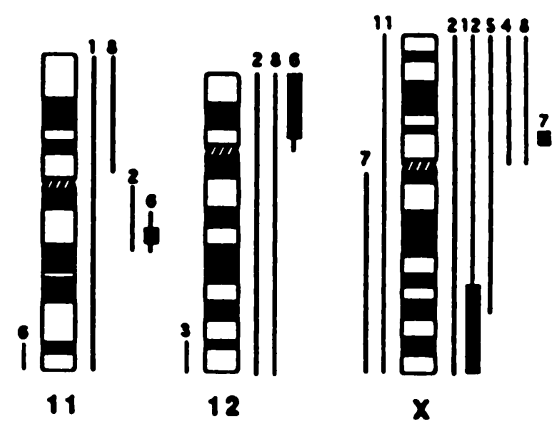

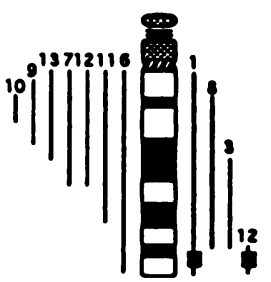

13

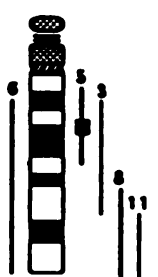

14

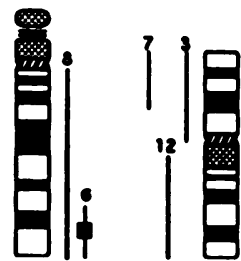

15

16
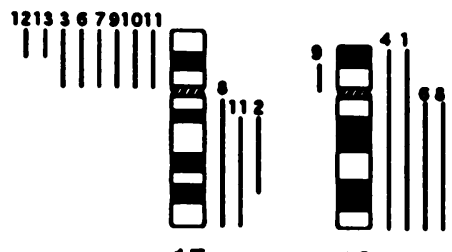

18

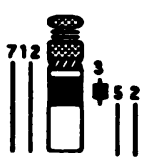

21

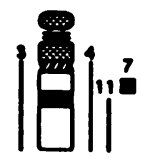

22

Fig. 3. Summary of genetic imbalances detected in 13 primary SCLC. Vertical lines on the left side of each chromosome idiogram represent loss of genetic material in the tumor, whereas those on the right side correspond to a gain. Changes in individual cases can be identified by the case number provided on the top of each line. Amplification sites are represented as solid squares or bars.

studies involving RFLP markers (25). In one case, the deleted region was restricted to chromosomal bands 3 p12-21.2. However, in the majority of cases the entire short arm was underrepresented. In 10 cases, we observed a simultaneous overrepresentation of the long arm. Such a result would be expected in case of an isochromosome $3 q$ formation. Isochromosomes are the cytogenetic correlate of low level amplification of many genes which might induce a growth advantage important for tumor initiation (26). Chromosome 5 frequently showed a similar pattern, i.e., the gain of the short arm was accompanied by the loss of $5 q$ in six cases. This result is suggestive for an isochromosome 5p. Both an isochromosome $3 q$ and an isochromosome $5 p$ were reported previously in cytogenetic analysis of SCLC, although less frequently than in our series of SCLC (27). The fact that, in addition to values reflecting a gain of $3 q$ and $5 p$, amplification sites were mapped to these chromosome arms might favor the hypothesis that not only the loss of heterozygosity on $3 p$ and $5 q$ but also the low level amplification of certain genes on $3 q$ and $5 p$ are important events in tumor initiation.

The frequent deletions of chromosomes $3 p$ and $5 q$ in SCLC are indicative for a pivotal mutation in tumor formation. Both chromosomal arms harbor at least one tumor suppressor gene, i.e., the von Hippel-Lindau gene on 3p25-26 and the FAP gene on 5q (28-30). 


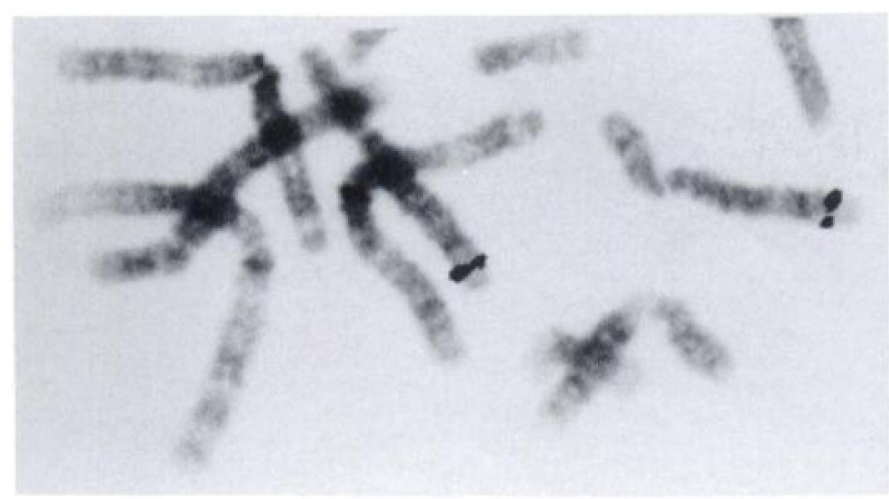

Fig. 4. Example of the chromosomal mapping position of an amplification site in SCLC case no. 3. The CGH experiment was performed on prometaphase chromosomes. Similar to the signals after hybridization with cosmid or YAC clones, two distinguished spots were detected, indicating the mapping position of amplified sequences in the tumor with high resolution. The signals are observed at chromosome band 8q24.1.

The contradictory results for loss of $3 p$ material using $\mathrm{CGH}$ and PCR-RFLP analysis, which we observed in one case (no. 1), can be explained by several cytogenetic events: (a) small, submicroscopical deletions which are beyond the resolution of $\mathrm{CGH}$ on metaphase chromosomes; (b) mitotic recombination; and (c) chromosome loss that was followed by reduplication (31). Both mitotic recombination and reduplication would result in $\mathrm{LOH}$ and uniparental disomy that would not be accompanied by copy number changes detectable with CGH. We observed LOH with primers for chromosomal bands 3p14 and 3p24. A deletion of that size would be clearly detectable by CGH. Thus, mitotic recombination or chromosome reduplication appear to be the more likely mechanisms that account for the described discrepancy. In all other cases (nos. 3-5, 7-9, and 13) where LOH studies were informative (19), the results were consistent with the CGH analysis.

The tumor suppressor genes $p 53$ and $R B$ are located on chromosomes $17 p$ and $13 q$, respectively (32). We observed partial and complete DNA loss on these chromosomal arms in 8 of $13(62 \%)$ and 7 of $13(54 \%)$ cases. The chromosome 13 losses were invariably accompanied with underrepresentation for $17 \mathrm{p}$. Both chromosomal loci are subject to allelic loss in SCLC as determined by LOH studies using RFLPs (33). An additional consensus region involved in losses was observed on the chromosomal band 10q24-25 in 5 of 13 cases. This region has not been reported previously to be deleted in lung cancer but is known to reveal LOH in e.g., glioblastoma and renal cell carcinoma (12). Loss of 11p was not observed in our collective, in contrast to previous LOH studies (12). Additional DNA losses were found on chromosomes $2 p, 4,8 p, 9 q, 16,11 q, 12 q, 18 p, 20 p, 21$, and 22.

The pattern of chromosomal gains and losses in SCLCs is very complex and involves virtually every site in the genome. This indicates a high genomic instability. Some chromosomes (e.g., 9, 13, 21, and 22) were involved in both gains and losses of the same subregions. This could possibly be explained as the result of random chromosomal changes which occur early in tumor development. Such random changes would be present in the predominant clone(s) and thus could be detected by CGH. However, some chromosomal sites were involved with much higher frequencies than others (see above), indicating their specific role in these tumors. It is a striking observation that chromosome arms $3 p, 5 q, 10 q$, and $17 p$ and chromosome bands $4 \mathrm{q} 31-35$, which were commonly deleted in these tumors, were never involved in gains of genetic material. From these data, it appears that random gains of these chromosome segments would be prohibitive with regard to the formation of SCLCs. An interesting observation in this respect was reported by Satoh et al. (34); the tumorigenic potential of a lung adenocarcinoma cell line was suppressed after the introduction of chromosomes 3 and 11 by means of cell fusion experiments.

Amplification of protooncogenes are a common feature of solid tumors $(35,36)$. A cytogenetic correlate is provided by double minute chromosomes or homogeneously staining regions. In contrast to deleted regions, amplifications usually reflect advanced and more aggressive tumor stages. In SCLC, amplification of the myc protooncogene family has been reported (37-39). We mapped the origin of amplicons to chromosome bands 1p31-32 (case nos. 3 and 7), 8q24 (case nos. 3 and 11), and 2p23 (case nos. 6 and 8). These sites harbour the L-myc, N-myc, and c-myc protooncogenes, respectively (40). Additionally, amplified regions were mapped to chromosomal sites containing genes of the ras family, i.e., $12 \mathrm{p}(\mathrm{v}-\mathrm{Ki}$-ras 2$)$. An additional site which showed overrepresentation in 4 of 13 cases was identified on chromosome 19q13.1. To our knowledge, no protooncogene has been mapped so far to this chromosome band. Candidate genes include the gene for the transforming growth factor (41) and a zinc finger gene (42). The possible involvement of these genes can now be tested by means of Southern blot analysis or PCR analysis.

Recent progress in solid tumor molecular biology, e.g., the identification of the gene for the familiar tumor syndrome von HippelLindau (30) and the FAP gene $(28,29)$, was achieved by positional cloning techniques. The identification of the chromosomal mapping position of commonly deleted or amplified loci in SCLC, as exemplified in this study, will streamline cloning efforts considerably. Future work will be focused on the identification of genetic changes specific for certain histologically defined lung cancers. Also, CGH of a higher case number, including primary tumors and metastatic sites, should contribute to identify those genetic aberrations that are responsible for a more aggressive clinical course, including the potential for metastasis.

\section{ACKNOWLEDGMENTS}

This study was supported by a grant from the Deutsche Krebshilfe and the Land Baden-Württemberg to T. C. The costs for the color figure were carried by Carl Zeiss, Oberkochen, Germany.

\section{REFERENCES}

1. Kallioniemi, A., Kallioniemi, O-P., Sudar, D., Rutovitz, D., Gray, J. W., Waldman, F., and Pinkel, D. Comparative genomic hybridization for molecular cytogenetic analysis of solid tumors. Science (Washington DC), 258: 818-821, 1992.

2. du Manoir, S., Speicher, M. R., Joos, S., Schröck, E., Popp, S., Döhner, H., Kovacs, G., Robert-Nicoud, M., Lichter, P., and Cremer, T. Detection of complete and partial chromosome gain and losses by comparative genomic in situ hybridization. Hum. Genet., 90: 590-610, 1993.

3. Joos, S., Scherthan, H., Speicher, M. R., Schlegel, J., Cremer, T., and Lichter, P. Detection of amplified DNA sequences by reverse chromosome painting using genomic tumor DNA as probe. Hum. Genet., 90: 584-589, 1993.

4. Kallioniemi, O-P., Kallioniemi, A., Sudar, D., Rutovitz, D., Gray, J. W., Waldman, F., and Pinkel, D. Comparative genomic hybridization: a rapid new method for detecting and mapping DNA amplification in tumors. Semin. Cancer Biol., 4: 41-46, 1993.

5. Schröck, E., Thiel, G., Lozanova, $T$, du Manoir, S, Meffert, M-C., Jauch, A Speicher, M. R., Nürnberg, P., Vogel, S., Jänisch, W., Donis-Keller, H., Ried, T., Witkowski, R., and Cremer, T. Comparative genomic hybridization of human malignant gliomas reveals multiple amplification sites and non-random chromosomal gains and losses. Am. J. Pathol., in press, 1994.

6. Speicher, M. R., du Manoir, S., Schröck, E., Holtgreve-Grez, H., Schoell, B., Lengauer, C., Cremer, T., and Ried, T. Molecular cytogenetic analysis of formalin fixed, paraffin embedded solid tumors by comparative genomic hybridization after universal DNA amplification. Hum. Mol. Genet., 2: 1907-1914, 1993.

7. DeVita, V. T., Hellman, S., and Rosenberg, S. A. (eds.) Cancer. Principles and Practice of Oncology. Philadelphia: J. B. Lippincott Co., 1989.

8. Heim, S., and Mitelman, F. Cancer Cytogenetics. New York: Alan R. Liss, Inc., 1987.

9. Cremer, T., Landegent, J., Brückner, A., Scholl, H. P., Schardin, M., Hager, H. D., Devilee, P., Pearson, and van der Ploeg, M. Detection of chromosome aberrations in the human interphase nucleus by visualization specific target DNAs with radioactive and non-radioactive in situ hybridization techniques: diagnosis of trisomy 18 with probe L1.84. Hum. Genet., 74: 346-352, 1986. 
10. Poddighe, P., Ramaekers, F. C. S., and Hopman, A. H. N. Interphase cytogenetics of tumors. J. Pathol., 166: 215-224, 1992.

11. Le Beau, M. M. Fluorescence in situ hybridization in cancer diagnosis. In: V. T. DeVita, S. Hellman, and S. A. Rosenberg (eds.), Important Advances in Oncology, pp. 29-45. Philadelphia: J. B. Lippincott Co., 1993.

12. Seizinger, B. R., Klinger, H. P., Junien, C., Nakamura, Y., Le Beau, M., Cavenee, W. Emanuel, B., Ponder, B., Nayle, S., Mitelman, F., Louis, D., Menon, A., Newsham, I., Decker, J., Kaelbling, M., Henry, I., and von Deimling, A. Report of the committee on chromosome and gene loss in human neoplasia. Cytogenet. Cell Genet., 58 . 1080-1096, 1991.

13. Sambrook, J., Fritsch, E. F., and Maniatis, T. Molecular Cloning: A Laboratory Manual. Cold Spring Harbor, NY: Cold Spring Harbor Laboratory, 1989.

14. WHO Histological Typing of Lung Tumours. Geneva: WHO, 1981.

15. Ried, T., Baldini, A., Rand, T. C., and Ward, D. C. Simultaneous visualization of seven different DNA probes by in situ hybridization using combinatorial fluorescence and digital imaging microscopy. Proc. Natl. Acad. Sci. USA, 89: 1388-1392, 1992.

16. Ganly, P. S., and Rabbitts, P. H. Polymerase chain reaction (PCR) for detection of MspI polymorphism at the D3S30 locus. Nucleic Acids Res., 19: 3757, 1992.

17. Ganly, P. S., and Rabbitts, P. H. Polymerase chain reaction (PCR) for detection of BamHI polymorphism at the THRB gene. Nucleic Acids Res., 19: 3757, 1992.

18. Sakurai, A., Bell, G. I., and DeGroot, L. J. Dinucleotide repeat polymorphism in the human thyroid hormone receptor $\beta$ gene (THRB) on chromosome 3. Nucleic Acids Res., 19: 6661, 1992.

19. Petersen, I., Reichel, M., Vogt, P., and Dietel, M. PCR-based RFLP-analysis for the detection of loss of heterozygosity on chromosomes $3 p$ and $5 q$ in human lung carcinomas. J. Cancer Res. Clin. Oncol., 119 (Suppl. 2): 60, 1993.

20. Whang-Peng, J., Kao-Shan, C. S., Lee, E. C., Bunn, P. A., Carney, D. N., Gazdar, A F., and Minna, J. D. Specific chromosome defect associated with human small-cel lung cancer: deletion 3p(14-23). Science (Washington DC), 215: 181-182, 1982.

21. Falor, W., Ward-Skinner, R., and Wegryn, S. A 3p deletion in small cell lung carcinoma. Cancer Genet. Cytogenet., 16: 175-177, 1985.

22. Zech, L., Bergh, J., and Wilson, K. Karyotypic characterization of established cell lines and short-term cultures of human lung cancers. Cancer Genet. Cytogenet., 15 335-347, 1985.

23. Sozzi, G., Bertoglio, M. G., Borello, M. G., Giani, S., Pilotti, S., and Della Porta, G Chromosomal abnormalities in a primary small cell lung cancer. Cancer Genet. Cytogenet., 27: 45-50, 1987.

24. Morstyn, G., Brown, J., Novak, U., Gardner, J., Bishop, J., and Garson, M. Heterogeneous cytogenetic abnormalities in small cell lung cancer cell lines. Cancer Res. 47: 3322-3327, 1987.

25. Yokota, J., Wada, M., Shimosato, Y., Terada, M., and Sugimura, T. Loss of heterozygosity on chromosomes 3,13 and 17 in small cell carcinoma and on chromosome 3 in adenocarcinoma of the lung. Proc. Natl. Acad. Sci. USA, 84: 9252-9256, 1987.

26. Solomon, E., Borrow, J., and Goddard, A. D. Chromosome aberration and cancer. Science (Washington DC), 254: 1153-1160, 1991.

27. Miura, I., Graziano, S. L., Cheng, J. Q., Doyle, A., and Testa, J. Chromosome alterations in human small cell lung cancer: frequent involvement of 5q. Cancer Res. 52: $1322-1328,1992$

28. Kinzler, K. W., Nilbert, M. C., Su, L-K., Vogelstein, B., Bryan, T. M., Levy, D. B. Smith, K. J., Preisinger, A. C., Hedge, P., McKechnie, D., Finniear, R., Markham, A.,
Groffen, J., Boguski, M. S., Altschul, S. F., Horii, A., Ando, H., Miyoshi, Y., Miki, Y., Nishisho, I., and Nakamura, Y. Identification of FAP locus genes from chromosome 5q21. Science (Washington DC), 253: 661-665, 1991.

29. Groden, J., Thilveris, A., Samowitz, W., Carlson, M., Gelbert, L., Albertsen, H., Joslyn, G., Stevens, J., Spiro, L., Robertson, M., Sargeant, L., Krapcho, K., Wolff, E., Burt, R., Hughes, J. P., Warrington, J., McPherson, J., Wasmuth, J., Le Paslier, D., Abderrahim, H., Cohen, D., Leppert, M., and White, R. Identification and characterization of the familial adenomatous polyposis coli gene. Cell, 66: 589-600, 1991.

30. Latif, F., Tory, K., Gnarra, J., Yao, M., Duh, F-M., Orcutt, M. L., Stackhouse, T., Kuzmin, I., Modi, W., Geil, L., Schmidt, L., Zhou, F., Li, H., Wei, M. H., Chen, F., Glenn, G., Choyke, P., Walther, M. M., Weng, Y., Duan, D-S., Dean, M., Glavac, D., Richards, F. M., Crossey, P. A., Ferguson-Smith, M. A., Le Paslier, D., Chumakov, I., Cohen, D., Chinault, A. C., Maher, E. R., Linehan, W. M., Zbar, B., and Lerman, $M$. I. Identification of the von Hippel-Lindau disease tumor suppressor gene. Science (Washington DC), 260: 1317-1320, 1993

31. Cavenee, W. K., Dryia, T. P., Phillips, R. A., Benedict, W. F., Godbout, R., Gallie, B. L., Murphree, A. L., Strong, L. C., and White, R. L. Expression of recessive alleles by chromosomal mechanisms in retinoblastoma. Nature (Lond.), 305: 779-784, 1984.

32. Knudson, A. G. Antioncogenes and human cancer. Proc. Natl. Acad. Sci. USA, 90: 10914-10921, 1993.

33. Mori, N., Yokota, J., Oshimura, M., Cavenee, W. K., Mizoguchi, H., Noguchi, M., Shimosato, Y., Sugimura, T., and Terada, M. Concordant deletions of chromosome 3p and loss of heterozygosity for chromosomes 13 and 17 in small cell lung carcinoma. Cancer Res., 49: 5130-5135, 1989.

34. Satoh, H., Lamb, P. C., Dong, J-T., Everitt, J., Boreiko, C., Oshimura, M., Barett, J. C. Suppression of tumorigenicity of A549 lung adenocarcinoma cells by human chromosomes 3 and 11 introduced via microcell-mediated chromosome transfer. Mol. Carcinog., 7: 157-164, 1993.

35. Alitalo, K., and Schwab, M. Oncogene amplification in tumor cells. Adv. Cancer Res., 47: 235-281, 1986.

36. Schimke, R. T. Gene amplification in cultured cells. J. Biol. Chem., 263: 5989-5992, 1988.

37. Wong, A. J., Ruppert, J. M., Eggleston, J., Hamilton, S. R., Baylin, S. B., and Vogelstein, B. Gene amplification of c-myc and $\mathrm{N}-m y c$ in small cell carcinoma of the lung. Science (Washington DC). 233: 461-464, 1986.

38. Brennan, J., O'Connor, T., Makuch, R. W., Simmons, A. M., Russell, E., Linnoila, R. I., Phelps, R. M., Gazdar, A. F., Ihde, D. C., and Johnson, B. E. myc family DNA amplification in 107 tumors and tumor cell lines from patients with small cell lung cancer treated with different combination chemotherapy regimens. Cancer Res., 51 : $1708-1712,1991$.

39. Birrer, M., and Brown, P. H. Application of molecular genetics to the early diagnosis and screening of lung cancer. Cancer Res., 52: 2658s-2664s, 1992.

40. Human Gene Mapping 11. Cytogenet. Cell Genet. 58: 1-2, 1991.

41. Schonk, D., Coerwinkel-Driessen, M., van Dalen, I., Oerlemans, F., Smeets, B., Schepens, J., Huslebos, T., Cockburn, D., Boyd, Y., Davis, M., Rettig, W., Shaw, D. Roses, A., Ropers, H., and Wieringa, B. Definition of subchromosomal intervals around the myotonic dystrophy gene region at 19q. Genomics, 4: 384-396, 1989.

42. Taylor, G. A., Lai, W. S., Oakey, R. J., Seldin, M. F., Shows, T. B., Eddy, R. L., and Blackshear, P. J. The human TIP protein: sequence, alignment with related proteins, and chromosomal localization. Nucleic Acids Res., 19: 3454-3459, 1991. 